\title{
Color Appearance of Decorative Coatings
}

\begin{abstract}
The article explains the basic concepts of colorimetry and deals with issues of assessment reflectance quality of special plaster coatings in accordance with current methods of measuring spectral reflectance of the International Commission on IIIumination (CIE). The results demonstrate that in the case of coatings with high gloss values leads to a linear increase of chroma depending on the lightness values in the case of measuring devices fitted diffusion geometry. Conversely, if the angle-measuring instrument fitted geometry values of specific purity correlated with values of specific brightness. Analysis BRDF, respectively BSRDF function showed that the previously used dichromatic spectral reflectance model must be extended by an additional parameter explaining the correlation between chroma and lightness at the di:8 measurement geometry.
\end{abstract}

Keywords: Colorimetry, Color space, BRDF, CIE geometric arrangement.

\section{Introduction}

A significant portion of color difference research revolves around the concept of color tolerances. The notion of color tolerance comes from the industrial quality control, where visual assessments have been routinely carried out to ensure that each new batch-color material falls within certain standards [1]. Color tolerance could be defined as the maximum magnitude of deviation from a particular point in color space (a "standard") beyond which the perceptual difference becomes noticeable to the normal human observer to such degree that the deviation cannot be accepted. In an ideal perceptually uniform color space the tolerance can be defined geometrically as a sphere around a chosen "standard" point. This is true when tolerance is defined in terms of "perceptibility." All points within the sphere belong to the "acceptable" category. In the absence of such an ideal space, non-ideal spaces maybe modified through the use of equations to set tolerances related to instrumental measurements.

The physical samples used to build the color-difference datasets are defined as "surface colors", (e.g. glossy automotive lacquer coating, paint, etc.). One of the main characteristics of these surface colors is relative surface uniformity and lack of surface relief under reference diffuse illumination. However, the appearance of object's color depends not only on spectral reflectance of the object, but also on the geometric characteristics of the reflective surface (gloss, texture, etc.).

The three-dimensional appearance of a texture with relief can be largely defined through the presence of shadows and highlights. There is also a colorimetric aspect that highlights contribute - specular highlights are characterized by the chromaticities of the viewing illuminant. Shadows accentuate the texture pattern. A combination of shadows and highlights has been proposed to shading, elicit cognitive mechanisms responsible for the perception of thus indicating to the visual system that an object surface is viewed. Xin et al. [2] showed that increasing the texture of a pairs of samples increased the acceptability of color differences. Thus, texture is an additional parametric effect that might need to be considered in the development of future color-difference metrics.

Regarding to influence of texture on color appearance the measuring geometry plays a crucial role in the measurement and assessment of color samples. Due to structural and surface features of the samples, the incident radiation reflected or transmitted in various directions shows spectral differences. The angle of incidence and the aperture angle of the illuminating beam of rays as well as the direction and aperture angle of the radiation detected by the detector have an impact on the colorimetric result. Former CIE standard 15.2 Colorimetry [3] recommends four

measuring geometries for colorimetry, including the $0^{\circ} / 45^{\circ}$ and $45^{\circ} / 0^{\circ}$ geometries together with two hemispherical geometries $0^{\circ} / \mathrm{d}$ and $\mathrm{d} / 0^{\circ}$ (Fig. 1). In this context, $d$ stands for observation of the light that is diffusely scattered by the sample by means of the wall of an integrating sphere or diffuse illumination of the sample by means of an integrating sphere.

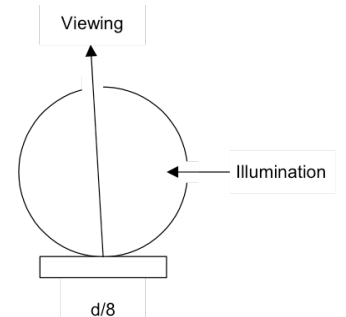

$d / 8$

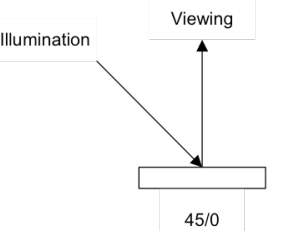

Fig.1. Former CIE recommendations for measuring geometries

Generally in the $45 / 0$ geometry, the mirror-reflecting component is eliminated deliberately to avoid falsification of the measuring result by gloss. Surfaces showing a preferred structural direction may yield different results depending on the relative position with respect to the incident light. Geometry with diffuse illumination or observation must be chosen in these cases. Diffuse illumination is accomplished by the use of an integrating sphere. Light introduced into the sphere is sent through a series of reflections off the diffuse white sphere wall, quickly resulting in the diffuse illumination incident on the sample. According to CIE definition, the axis of the beam of rays must be tilted by no more than $10^{\circ}$ with respect to the surface normal upon perpendicular illumination or observation of the sample. This is made possible by the $\mathrm{d} / 8^{\circ}$ measuring geometry, which offers particular advantages in the measurement of glossy or structured samples. Observation of the diffusely illuminated sample under an angle of $8^{\circ}$ allows the influence of the mirrorreflected component of glossy samples to be eliminated by inserting a beam trap in the integrating sphere.

In new CIE standard 15.3 Colorimetry [4] is therefore recommended nomenclature for diffuse: eight-degree 
geometry, specular component included $\left(\mathrm{di}: 8^{\circ}\right)$, eightdegree geometry, specular component excluded (de: $8^{\circ}$ ) and it's inverse alternatives $\left(8^{\circ}: \mathrm{di}, 8^{\circ}: \mathrm{de}\right)$, beside diffuse/diffuse (d:d) and alternative diffuse geometry $\left(\mathrm{d}: 0^{\circ}\right)$.

Traditionally, optical propagation has been treated as consisting of two distinct phenomena: regular (specular) propagation and diffuse propagation. However, while purely regular (specular) or purely diffuse propagation can be very closely approximated, neither is ever completely and independently achieved in practice.

In reflection we have a transfer function that records for a given incoming direction, the amount of light that is reflected in a certain outgoing direction. The function is called "BRDF" (bi-directional reflectance distribution function). It's four-dimensional function written as $f_{\mathrm{r}}\left(x, \omega_{i}, \omega_{r}\right)$ or $f_{\mathrm{r}}\left(\omega_{i} \rightarrow \omega_{r}\right)$. Since $\mathrm{d} E(x, \omega)=L(x, \omega) \cos \theta d \omega$, we multiply the irradiance by the transfer function and get the amount of light, in radiance, going in the outgoing direction:

$$
f_{r}\left(x, \omega_{i}, \omega_{r}\right)=\frac{d L\left(x \rightarrow \omega_{r}\right)}{L_{i}\left(x \leftarrow \omega_{i}\right) \cos \theta_{i} d \omega_{i}}
$$

If examined isotropic surface, the BRDF function depends only on three variables $\theta_{i}, \Phi_{i} \theta_{r}$, since the reflectivity of the surface is symmetrical with respect to the plane of incidence and perpendicular to the surface does not change in the case when the surface rotates around its normal. This theoretical solution is based on the assumption of a homogeneous dielectric when considering reflection at the interface of two media. Near of real objects is necessary to assume dielectric inhomogeneous, where there is a reflection at the interface of two media (this reflection is often referred to as primary) and the reflection of body dielectric material (this reflection is referred to as secondary or diffusion). The resulting reflection is formed as an additive component of primary (surface) reflection $\boldsymbol{L}_{S}$ and secondary component (diffuse) reflection $\boldsymbol{L}_{\boldsymbol{B}}$. Shafer [5] showed, that spectral characteristics of reflection at the interface and within the dielectric body itself are invariant to illumination angle.

$$
L(\theta, \lambda)=m_{S}(\theta) c_{S}(\lambda)+m_{B}(\theta) c_{B}(\lambda)
$$

Where $\boldsymbol{m}_{S}$ a $\boldsymbol{m}_{\boldsymbol{B}}$ are factors geometric scaling, $\boldsymbol{c}_{S}$ a $\boldsymbol{c}_{\boldsymbol{B}}$ are spectral characteristics of the reflection at the interface and inside the body, where is:

$$
\begin{aligned}
& c_{S}(\lambda)=E(\lambda) R_{S}(\lambda) \\
& c_{B}(\lambda)=E(\lambda) R_{B}(\lambda),
\end{aligned}
$$

with $E(\lambda)$ - spectral power distribution of used light, $\boldsymbol{R}_{S}(\lambda)$ - spectral reflectance factor at the interface $\boldsymbol{R}_{B}(\lambda)$ - spectral reflectance factor inside the body.

Our previous work showed that specific textures used in decorative coatings can affect anomalies in measured color values [6].

$$
L(\theta, \lambda)=m_{S}(\theta) c_{S}(\lambda)+m_{B}(\theta) c_{B}(\lambda)+m_{L}(\theta) c_{L}(\lambda)
$$

where $\boldsymbol{m}_{L}$ is factor geometric scaling, $\boldsymbol{c}_{L}$ is spectral characteristics of the reflection at covering layer of decorative paint. This enhancement of formula (2) via expected additivity allowing description of optical properties an acrylic varnish overcoat. This overcoat itself gives a smooth, high gloss finish.

\section{Materials and methods}

In the company AVIS COLOR was ready to set hardboard panel with a thickness of $5 \mathrm{~mm}$ and a square size $80 \times 80 \mathrm{~cm}$, which was applied decorative coatings Italian company OIKOS.
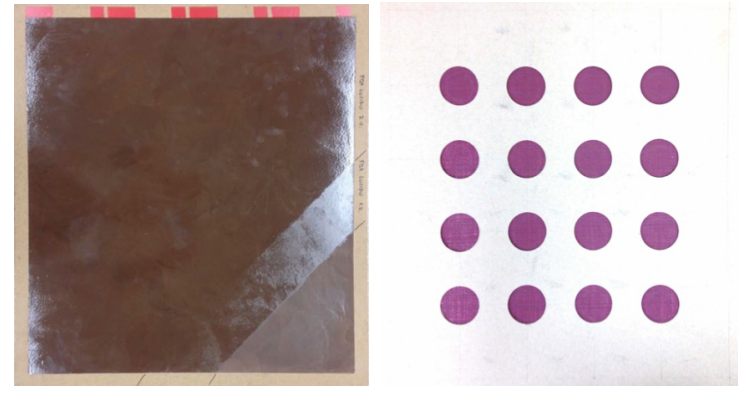

Fig.2 Hardboard panel FBA LUCIDO + example of measuring mask

Hardboard FBA LUCIDO contains four different layers, from which three are visible in Figure 2. First layer is is etcher, which is coated on hardboard, than was used base coat (matte part of our sample in right bottom corner). For final finish were used two layers of clear coat, because only one layer cover base coat insufficiently as visible in Figure 2 - semi-matte strip above uncovered base coat in right bottom corner.

For measuring of the spectral characteristics of this fancy paint were used two portable devices with different geometric configuration: MiniScan XE (HunterLab, USA) with a geometry of $45^{\circ} \mathrm{a}: 0^{\circ}$ (annular illumination on $45^{\circ}$ ), the spectral range $400-700 \mathrm{~nm}$, spectral bandwidth $10 \mathrm{~nm}$, aperture diameter $30 \mathrm{~mm}$, used light source: D65 simulator based on discontinuous Xenon lamps. The second device was Microflash MF200d (Datacolor International, USA) with two modes of viewing geometry di: $8^{\circ}$ and de: $8^{\circ}$, spectral range 400-700nm, extrapolated spectral measurement step $10 \mathrm{~nm}$ bandwidth, aperture diameter $20 \mathrm{~mm}$, used light source: D65 simulator based discontinuous Xenon lamp. Sample was measured 10 times at 16-measuring points, which formed a square coordinate grid $4 \times 4$ points by measuring mask (Figure 2). In total, were made 480 individual measurements in vertical and horizontal orientation of the device to the network, coordinate, which was subsequently evaluated using data treatment software Gigawiz Aabel, v. 3.0.

Gloss values were captured by Zehntner ZGM 1110 gloss meter at three viewing angles $20^{\circ}, 60^{\circ}$ and $85^{\circ}$. Following recommendation in ASTM standard D523 was chosen for comparison only $20^{\circ}$ values [7].

\section{Results and discussion}

Reflectance on the opaque object is containing generally two parts as mentioned in equation (2). It is visible that spectral characteristic $c_{S}$ is dependent on spectral power distribution of used light and spectral reflectance at the interface - equation (3). An effect of spectral reflectance of body and interface was measured by subtractive method of diffuse viewing geometry. That means, if di: $8^{\circ}$ viewing geometry collect whole reflected light and de: $8^{\circ}$ viewing geometry extract specular part of reflectance, than difference between reflectance values measured by using of these two viewing geometries will show us portion of specularly reflected light: $\boldsymbol{\Delta d}=$ di: $8^{\circ}-$ de: $8^{\circ}$. This method was confirmed on red Ceram Colour Standard from CCS II set. Spectral reflectance data on graph in Figure 3 are showing that specular reflectance is achromatic $-\Delta \mathrm{d}: 8^{\circ}$ $(\boldsymbol{\Delta d})$ curve is parallel with wavelength axis. 


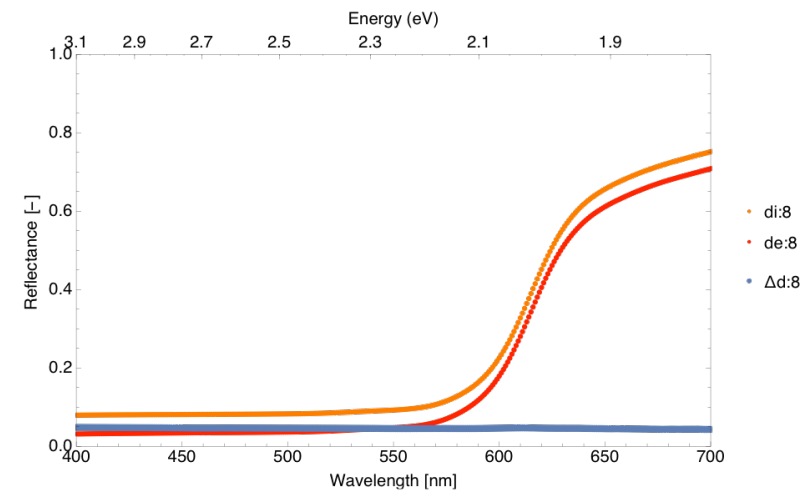

Fig.3 Spectral reflectance of CCSII RED tile

Following equation (2) we can assume that $\boldsymbol{R}_{S}(\lambda)$ is equal to $\boldsymbol{\Delta d}$. That means $\boldsymbol{m}_{\boldsymbol{S}}$ is dependent on roughness of measured dielectric body. An optically smooth or flat surface is glossy in appearance. A priory it we can use measurement of $\boldsymbol{\Delta d}$ for gloss prediction. As confirmation of this idea we have measured set of black samples with different gloss by subtractive method of diffuse viewing geometry and by tri-glossmeter Zehntner. As shown on graph in Figure 4 we obtain three different relations based on different gloss viewing angles, which were fitted by 3order polynomial functions:

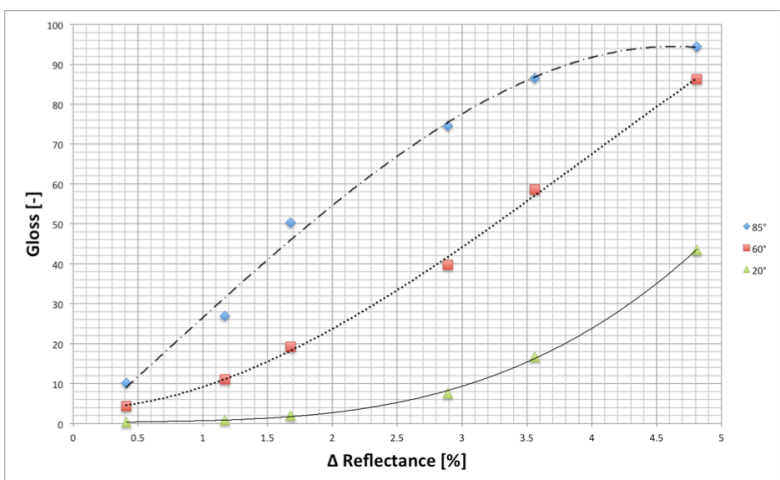

Fig.4 Relationship between reflectance $\boldsymbol{\Delta d}$ and gloss values

Following recommendation in ASTM standard D523 was chosen for comparison only $20^{\circ}$ values as mentioned before for which we obtain specific coefficients of polynomial fitting:

(6) $G L S_{20^{\circ} p}=0,3678(\Delta \mathrm{d})^{3}-0,1379(\Delta \mathrm{d})^{2}+0,1479(\Delta \mathrm{d})+0,2707$

If we are looking on computing of colorimetric parameters, it is important to understand that the gloss of samples will mainly affect lightness values. The bottom graph of Figures 5-7 shows lightness map of sample FBA LUCIDO measured by three different viewing geometries. Fro representation of each measured point of sample was used rectangular $\mathrm{x}$ and $\mathrm{y}$ coordinates together with Delaunay triangulations. It is visible good agreement between $45^{\circ} \mathrm{a}: 0^{\circ}$ and de: $8^{\circ}$ viewing geometry in point of view of surface quality difference evaluation.

The graph of Figure 7 confirms premise of minimal differences in lightness $L^{*}$ between individual points of FBA LUCIDO sample due to collection of whole reflected light by di: $8^{\circ}$ viewing geometry. Beside that it is visible higher lightness values in comparison to specular component excluded viewing geometries $\left(45^{\circ} \mathrm{a}: 0^{\circ}\right.$ and de: $\left.8^{\circ}\right)$.

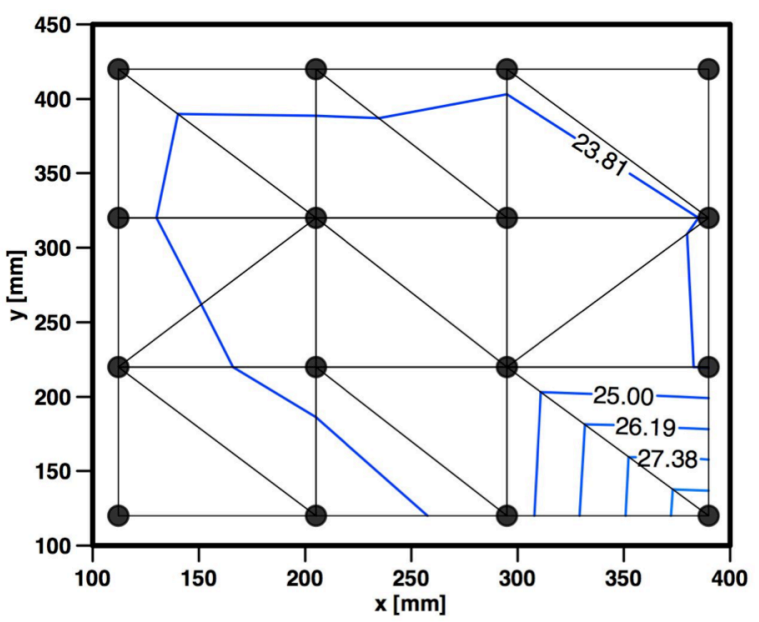

Fig.5 FBA LUCIDO $45^{\circ} \mathrm{a}: 0^{\circ}-\mathrm{CIE} \mathrm{L}$

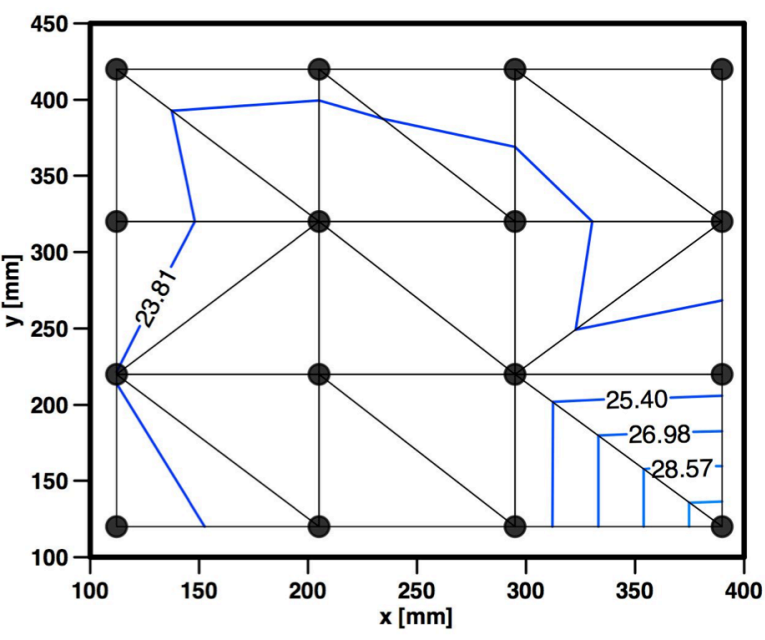

Fig.6. FBA LUCIDO de: $8^{\circ}$ - CIE L

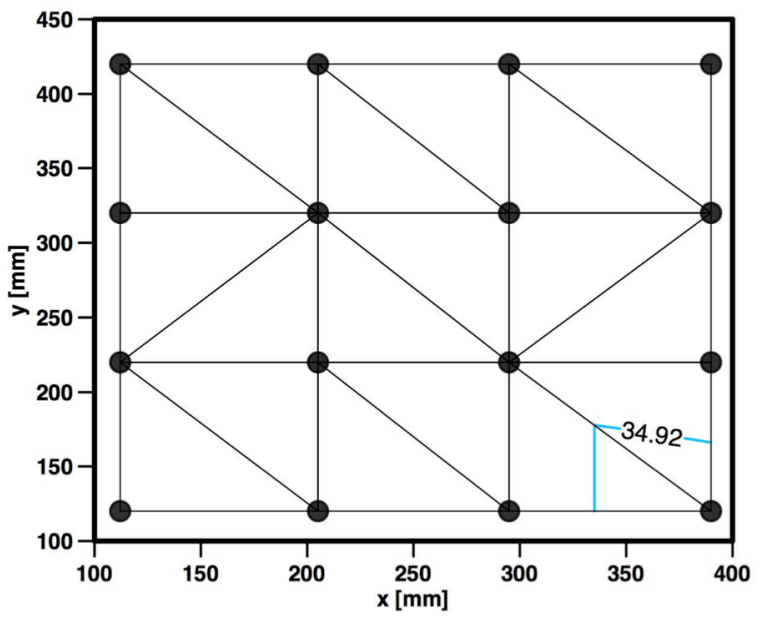

Fig.7. FBA LUCIDO di:8- CIE L 
Following this confirmation of theoretical assumptions we have tried to apply equation (6) for prediction of gloss values at viewing angle $20^{\circ}$. The bottom graph of Figures 89 shows gloss map of sample FBA LUCIDO. It is visible that predicted gloss values are similar in trend to measured values (correlation coefficient $=0,67$ ), nevertheless in point of view of whole appearance of isogloss lines are visible differences mainly in point with coordinate $(295,120)$.

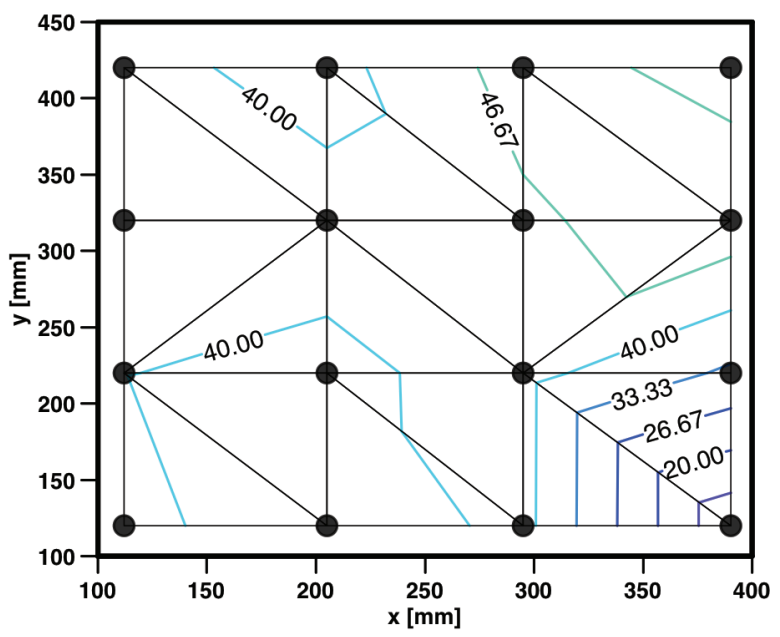

Fig.8. FBA LUCIDO predicted Gloss 20

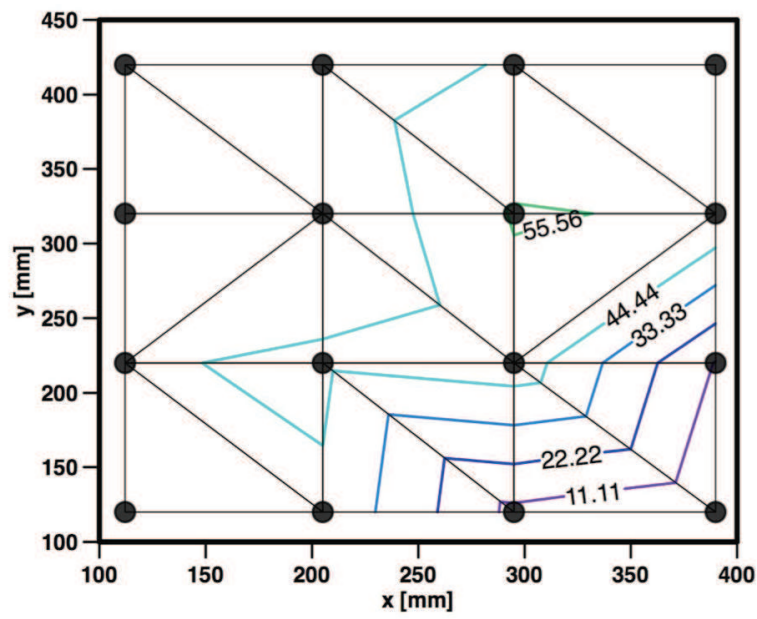

Fig.9. FBA LUCIDO measured Gloss $20^{\circ}$

This difference is probably caused by different size of measuring aperture. The Datacolor spectrophotometer MF200 was equipped by LAV aperture with $20 \mathrm{~mm}$ diameter. The Zehntner ZGM 1110 gloss meter has three different apertures, dependently on viewing angle. In our case: $20^{\circ}$ has measured are $4.2 \mathrm{~mm} \times 2 \mathrm{~mm}$, based on that measurement of gloss by Zehntner gloss meter is much sensitive on local roughness differences in comparison to spectrophotometer, which collect reflectance form area of $1256 \mathrm{~mm}^{2}$.

\section{Conclusion}

Instrument geometry refers to the physical makeup of the color measuring instrument; relating specifically to the nature and position of the light source, and the angles of the viewing optics. A color difference assessment will indicate that the glossy sample is darker and more saturated than the matte sample.

The paper explains the basic concepts of colorimetry and deals with issues of assessment reflectance quality of special materials coatings in accordance with current methods of measuring spectral reflectance of the International Commission on Illumination (CIE).

Furthermore, it was shown that in the case of the local gloss values prediction is possible to use subtractive method of diffuse viewing geometry $\boldsymbol{\Delta d}$.

\section{Acknowledgments}

The Czech Ministry of Education supported this work, project LO1213

\section{REFERENCES}

[1] Vik M.,"Colour difference formula evaluation on LCAM textile data, Vlakna a Textil, 10 (3, 126-129, 2003

[2] Xin, J.H., Shen, H.-L., LamM, C.C. Investigation of texture effect on visual colour difference evaluation. Col. Res. \& Appl., 30, 341-347, 2005

[3] CIE 15.2 Colorimetry, 1986, ISBN 3900734003

[4] CIE 15-2004 Colorimetry, ISBN 9783901906336

[5] Shafer, S.A. Using color to separate reflection components, Color Research and Application, 10(4): 210-218, 1985.

[6] Vik, M., Viková, M., Maltseva, A., Čejka, V.: Complex color non-uniformity and surface texture, 20th international conference STRUTEX, Liberec, December 1 - 2, 2014, pp. 95101, ISBN 978-80-7494-139-9

[7] ASTM D523 - 14, Standard Test Method for Specular Gloss

[8] Hunter, R; and Harold, R.: The Measurement of Appearance, John Wiley \& Sons, 1987, p. 78.

\begin{abstract}
Authors:
doc. Ing. Michal Vik, Ph.D., Technická univerzita v Liberci, Fakulta textilní, Laboratoř Měření Barevnosti a Vzhledu, Studentská 2, 46117 Liberec, Czech Republic, e-mail: michal.vik@tul.cz
\end{abstract}

Ing. Václav Čejka, Ph.D., IVÚTS, a.s., Svárovská 619, Liberec, 460 01, Czech Republic, vaclav.cejka@vuts.cz

Ing. Martina Viková, PhD., Technická univerzita v Liberci, Fakulta textilní, Laboratoř Měření Barevnosti a Vzhledu, Studentská 2, 46117 Liberec, Czech Republic, e-mail: martina.vikova@tul.cz

Anna Maltseva, MgA., Technická univerzita v Liberci, Fakulta textilní, Laboratoř Měření Barevnosti a Vzhledu, Studentská 2, 46117 Liberec, Czech Republic, e-mail: an.malce@yandex.com 